\title{
Implementasi Fuzzy Decision Making Untuk Pemilihan Marketplace
}

\author{
Era Yunianto ${ }^{1}$, Taryadi $^{2}$ \\ email: era.yunianto@gmail.com ${ }^{1}$, taryadi.pk1@gmail.com ${ }^{2}$ \\ Program Studi Sistem Informasi - STMIK Widya Pratama ${ }^{1,2}$
}

\begin{abstract}
Abstrak
Pandemi covid-19 sangat berpengaruh terhadap perekonomian khususnya UMKM. Dengan diberlakukannya pembatasan sosial berskala besar, maka berdampak terhadap pendapatan UMKM. Berjualan melalui emarketplace merupakan salah satu cara penyesuaian terhadap kondisi saat ini . Salah satu faktor dalam keberhasilan adalah tepat dalam memilih e-marketplace. Penelitian ini bertujuan mengimplementasikan metode fuzzy decision making pada proses pemilihan e-marketplace. Kriteria yang digunakan antara lain : kualitas pelayanan, kualitas sistem, kualitas sistem informasi dan kualitas penyedia layanan. Alternatif dalam penelitian ini merupakan peringkat tiga besar e-marketplace di Indonesia tahun 2020. hasil seleksi alternatif diperoleh urutan alternatif berdasarkan nilai total integral yaitu $\mathrm{SH}>\mathrm{TP}>\mathrm{BL}$. e-marketplace $\mathrm{SH}$ dapat dijadikan alternatif terbaik sebagai media pemasaran melalui internet.
\end{abstract}

Kata kunci : Pemilihan e-marketplace , Fuzzy Decision Making

\section{Pendahuluan}

Pandemi covid-19 berpengaruh terhadap perekonomian. Dalam laporan OECD, UMKM Indonesia yang merupakan tulang punggung ekonomi nasional sangat berdampak covid-19. Tidak hanya pendapatan yang terus menurun, produksi dan tenaga kerja juga dikurangi. Rendahnya tingkat digitalisasi, kesulitan pengaksesan teknologi dan rendahnya pemahaman strategi bisnis merupakan penyebab UMKM sangat berdampak covid-19. dengan kondisi ini, UMKM harus dapat menyesuaikan diri terhadap perkembangan zaman. [1][2]

Dengan diberlakukannya pembatasan sosial berskala besar, maka berdampak pada operasional UMKM dan konsumen yang berbelanja langsung juga mengalami penurunan jumlah. Berjualan melalui emarketplace atau memanfaatkan elektronik dalam promosi dan penjualan merupakan cara penyesuaian terhadap kondisi saat ini [3]. Penjualan melalui e-marketplace berdampak positif dan signifikan terhadap pendapatan UMKM [4] . Memilih e-marketplace yang tepat sangat berdampak terhadap profitabilitas UMKM [5].

Terdapat beberapa kriteria yang mempengaruhi pengguna dalam pemilihan emarketplace antara lain kualitas pelayanan, kualitas sistem, kualitas informasi dan kualitas penyedia layanan [6]. Dari kriteria diatas, diperlukan metode dalam pengambilan keputusan dalam pemilihan e-marketplace terbaik dari sejumlah alternatif. Metode yang pernah digunakan pemilihan e-marketplace antara lain metode Fuzzy AHP [7][8] , Fuzzy AHP MOORA [9], Fuzzy AHP VIKOR[10], dan Fuzzy AHP TOPSIS[11].

Metode fuzzy sering digunakan karena dapat mengolah data yang mengandung ketidakpastian. beberapa penelitian menggunakan metode fuzzy decision making terbukti memiliki kinerja sangat baik [12]. Selain dalam pemilihan e-marketplace, metode fuzzy juga dapat diimplementasikan dalam vendor atau supplier [13][14] , pemilihan perusahaan pengiriman makanan online [15], pemilihan lokasi usaha [16] dan evaluasi LMS [17].

Tujuan dari penelitian ini adalah mengembangakan metode fuzzy decision making untuk pemilihan e-marketplace terbaik, karena pemilihan e-marketplace berpengaruh terhadap peningkatan pendapatan. Data penelitian diambil pada kuartal terakhir tahun 2020. Hasil dari penelitian ini, dapat menjadi referensi dalam pemilihan e-marketplace.

\section{Metode Penelitian}

Penelitian ini merupakan penelitian eksperimental pemilihan e-marketplace dengan menggunakan metode fuzzy decision making. Sumber data penelitian ini diperoleh dari kuesioner yang diisi oleh pengguna emarketplace. Alternatif yang digunakan pada 
penelitian ini merupakan tiga besar emarketplace dengan pengunjung terbanyak pada tahun 2020 yaitu SH, TP dan BL [18]. responden yang mengisi kuesioner, pernah menggunakan e-marketplace diatas.

Dalam penelitian ini, kriteria yang digunakan ditunjukan pada tabel 1 [19].

Tabel 1. Kriteria Penelitian

\begin{tabular}{|c|c|}
\hline $\begin{array}{c}\text { Kriteria / Sub } \\
\text { Kriteria } \\
\end{array}$ & Definisi \\
\hline $\begin{array}{ll}\text { 1. } & \text { Kualitas } \\
& \text { Pelayanan }\end{array}$ & $\begin{array}{l}\text { Penilaian pelayanan } \\
\text { terhadap pengguna }\end{array}$ \\
\hline a. trust & $\begin{array}{c}\text { Penciptaan rasa } \\
\text { kepercayaan }\end{array}$ \\
\hline b. reliability & $\begin{array}{c}\text { Konsistensi layanan } \\
\text { yang dijanjikan }\end{array}$ \\
\hline c. responsiveness & $\begin{array}{c}\text { Kemampuan untuk } \\
\text { merespon tepat waktu }\end{array}$ \\
\hline 2. kualitas sistem & $\begin{array}{c}\text { Kemampuan } \\
\text { infrastruktur teknis } \\
\text { dalam melaksanakan } \\
\text { layanan yang } \\
\text { diharapkan }\end{array}$ \\
\hline a. navigability & Navigasi yang mudah \\
\hline b. response time & $\begin{array}{l}\text { Waktu respon aplikasi } \\
\text { / web }\end{array}$ \\
\hline c. accessibility & $\begin{array}{c}\text { Dapat diakses setiap } \\
\text { saat }\end{array}$ \\
\hline d. security & Keamanan sistem \\
\hline e. usability & $\begin{array}{c}\text { Aplikasi / web mudah } \\
\text { dipelajari dan } \\
\text { digunakan }\end{array}$ \\
\hline 3. kualitas informasi & $\begin{array}{c}\text { Kemampuan dalam } \\
\text { penyampaian } \\
\text { informasi } \\
\end{array}$ \\
\hline a. accuracy & $\begin{array}{c}\text { Akurat/benar/tepat } \\
\text { dalam memberikan } \\
\text { informasi }\end{array}$ \\
\hline b. completeness & $\begin{array}{c}\text { Kelengkapan } \\
\text { informasi }\end{array}$ \\
\hline c. timeliness & $\begin{array}{c}\text { Informasi yang terkini } \\
\text { / up to date }\end{array}$ \\
\hline d. relevance & $\begin{array}{c}\text { Informasi sesuai } \\
\text { dengan layanan yang } \\
\text { disediakan }\end{array}$ \\
\hline $\begin{array}{l}\text { e. understandabili } \\
\text { ty }\end{array}$ & $\begin{array}{c}\text { Informasi mudah } \\
\text { dipahami }\end{array}$ \\
\hline 4. kualitas vendor & $\begin{array}{l}\text { Penilaian objektif } \\
\text { penyedia layanan }\end{array}$ \\
\hline a. awareness & $\begin{array}{l}\text { Reputasi e- } \\
\text { marketplace }\end{array}$ \\
\hline b. price savings & $\begin{array}{l}\text { Keuntungan/harga/bo } \\
\text { nus yang diberikan. }\end{array}$ \\
\hline
\end{tabular}

Berikut langkah penelitian dalam fuzzy decision making : [20]

\section{A. Representasi masalah}

Aktivitas yang dilakukan pada tahap ini yaitu
1) Identifikasi tujuan dan kumpulan alternatif

2) Identifikasi kriteria

3) membangun struktur hirarki masalah

B. Evaluasi himpunan fuzzy

Aktivitas yang dilakukan pada tahap ini antara lain :

1) Memilih himpunan rating untuk bobot kriteria dan derajat kecocokan alternatif terhadap kriteria.

2) Melakukan evaluasi terhadap bobot kriteria dan derajat kecocokan alternatif pada kriteria.

3) Melakukan Agregasi terhadap bobot kriteria dan derajat kecocokan alternatif pada kriteria.

Jika $\mathrm{W}_{\mathrm{t}}$ merupakan bobot dari kriteria $\mathrm{C}_{\mathrm{t}}$ dan $S_{i t}$ merupakan rating fuzzy derajat kecocokan alternatif $A_{i}$ terhadap kriteria $\mathrm{C}_{\mathrm{t}}$, maka $\mathrm{F}_{\mathrm{i}}$ merupakan indeks kecocokan fuzzy dari alternatif $A_{i}$ dapat diperoleh dari agregasi $S_{i t}$ dan $W_{t}$ melalui persamaan ( 1 )

$F_{i}=\left(\frac{1}{k}\right)\left[\left(S_{i 1} \otimes W_{1}\right) \oplus\left(S_{i 2} \otimes W_{2}\right) \oplus\right.$

$\left.\cdots \oplus\left(S_{i k} \otimes W_{k}\right)\right] \quad(1)$

Dengan $\mathrm{S}_{\mathrm{it}}=\left(\mathrm{O}_{\mathrm{it}}, \mathrm{P}_{\mathrm{it}}, \mathrm{Q}_{\mathrm{it}}\right)$ dan $\mathrm{W}_{\mathrm{t}}=\left(\mathrm{a}_{\mathrm{t}}, \mathrm{b}_{\mathrm{t}}\right.$, $c_{t}$ ) merupakan bilangan fuzzy segitiga.

\section{Seleksi alternatif yang optimal}

Aktivitas yang dilakukan yaitu memprioritaskan alternatif menggunakan agregasi. Alternatif dengan prioritas tertinggi sebagai hasil alternatif optimal. Menggunakan metode nilai total integral dalam melakukan agregasi. Misal F (a, b, c) adalah bilangan fuzzy segitiga, sehingga nilai total integral dapat dihitung menggunakan persamaan (2).

$$
I_{T}^{\alpha}(F)=\left(\frac{1}{2}\right)(\alpha c+b+(1-\alpha) a)
$$

$\alpha$ merupakan indek / derajat keoptimisan pengambil keputusan yang bernilai $0 \leq \alpha$ $\leq 1$. semakin besar nilai $\alpha$ menunjukan derajat keoptimisan semakin besar.

\section{Hasil dan Pembahasan}

Berikut hasil dari langkah implementasi fuzzy decision making untuk pemilihan emarketplace :

Langkah 1 : Representasi masalah

Tujuan dalam penelitian ini adalah memilih e-marketplace terbaik berdasarkan kriteria yang telah ditentukan. Terdapat tiga 
alternatif dalam penelitian ini yaitu $A=\left\{A_{1}\right.$, $\left.\mathrm{A}_{2}, \mathrm{~A}_{3}\right\}$ dengan $\mathrm{A}_{1}=\mathrm{SH}, \mathrm{A}_{2}=\mathrm{TP}$ dan $\mathrm{A}_{3}=$ $\mathrm{BL}$.

Terdapat 4 kriteria utama yaitu $\mathrm{C}=\left\{\mathrm{C}_{1}\right.$, $\left.\mathrm{C}_{2}, \mathrm{C}_{3}, \mathrm{C}_{4}\right\}$, dengan $\mathrm{C}_{1}=$ kualitas pelayanan, $\mathrm{C}_{2}=$ kualitas sistem, $\mathrm{C}_{3}=$ kualitas informasi dan $\mathrm{C}_{4}=$ kualitas vendor. Terdapat 3 sub kriteria dari kualitas pelayanan yaitu $\mathrm{C}_{1}=\{$ $\left.\mathrm{C}_{11}, \mathrm{C}_{12}, \mathrm{C}_{13}\right\}$ dengan $\mathrm{C}_{11}=$ trust, $\mathrm{C}_{12}=$ reliability dan $\mathrm{C}_{13}=$ responsiveness. Terdapat 5 sub kriteria dari kualitas sistem yaitu $\mathrm{C}_{2}=\{$ $\left.\mathrm{C}_{21}, \mathrm{C}_{22}, \mathrm{C}_{23}, \mathrm{C}_{24}, \mathrm{C}_{25}\right\}$ dengan $\mathrm{C}_{21}=$ navigability, $\mathrm{C}_{22}=$ response time, $\mathrm{C}_{23}=$ accessibility, $\mathrm{C}_{24}=$ security dan $\mathrm{C}_{25}=$ usability. Terdapat 5 sub kriteria dari kualitas informasi yaitu $\mathrm{C}_{3}=\left\{\mathrm{C}_{31}, \mathrm{C}_{32}, \mathrm{C}_{33}, \mathrm{C}_{34}, \mathrm{C}_{35}\right.$ \} dengan $\mathrm{C}_{31}=$ accuracy, $\mathrm{C}_{32}=$ completeness, $\mathrm{C}_{33}=$ timeliness, $\mathrm{C}_{34}=$ relevance dan $\mathrm{C}_{35}=$ understandability. Terdapat 2 sub kriteria dari kualitas vendor yaitu $\mathrm{C}_{4}=\left\{\mathrm{C}_{41}, \mathrm{C}_{42}\right\}$ dengan $\mathrm{C}_{41}=$ awareness dan $\mathrm{C}_{42}=$ price savings.

Struktur hirarki masalah disajikan pada gambar 1.

Langkah 2 : Evaluasi himpunan fuzzy

Variabel linguistik yang digunakan dalam evaluasi rating untuk bobot kriteria yaitu $\mathrm{W}=\{\mathrm{SR}, \mathrm{R}, \mathrm{C}, \mathrm{T}, \mathrm{ST}\}$ dengan $\mathrm{SR}=$ Sangat Rendah; R=Rendah; $\mathrm{C}=$ Cukup; $\mathrm{T}=$ Tinggi; $\mathrm{ST}=$ Sangat Tinggi.

Variabel linguistik yang digunakan dalam evaluasi derajat kecocokan alternatif terhadap kriteria yaitu, $\mathrm{S}=\{\mathrm{SK}, \mathrm{K}, \mathrm{C}, \mathrm{B}, \mathrm{SB}\}$, dengan $\mathrm{SK}=$ Sangat Kurang; $\mathrm{K}=$ Kurang ; $\mathrm{C}=$ Cukup ; $\mathrm{B}=$ Baik ; $\mathrm{SB}=$ Sangat Baik.

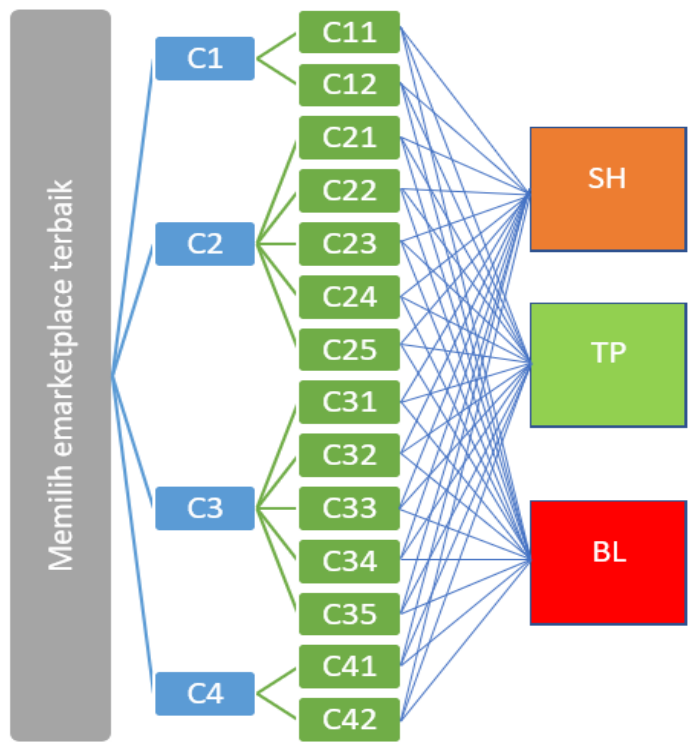

Gambar 1. Struktur Hirarki Masalah

Variabel linguistik direpresentasikan dengan bilangan fuzzy segitiga yang ditunjukan pada tabel 2.
Tabel 2. Bilangan fuzzy Segitiga

\begin{tabular}{cc}
\hline $\begin{array}{c}\text { Variabel } \\
\text { Lingustik }\end{array}$ & $\begin{array}{c}\text { Bilangan Fuzzy } \\
\text { Segitiga }\end{array}$ \\
\hline SR / SK & $(0,0,0.25)$ \\
\hline R / K & $(0,0.25,0.5)$ \\
\hline C & $(0.25,0.5,0.75)$ \\
\hline T / B & $(0.5,0.75,1)$ \\
\hline ST / SB & $(0.75,1,1)$ \\
\hline
\end{tabular}

Tabel 3 merupakan hasil dari evaluasi bobot kriteria dan derajat kecocokan alternatif terhadap kriteria yang diberikan oleh responden.

Tabel 3. Evaluasi bobot kriteria

\begin{tabular}{ccc}
\hline Kriteria / Sc & Rating & Bobot \\
\hline C1 & C & $(0.25,0.5,0.75)$ \\
\hline C11 & C & $(0.25,0.5,0.75)$ \\
\hline C12 & C & $(0.25,0.5,0.75)$ \\
\hline C13 & C & $(0.25,0.5,0.75)$ \\
\hline C2 & T & $(0.5,0.75,1)$ \\
\hline C21 & T & $(0.5,0.75,1)$ \\
\hline C22 & T & $(0.5,0.75,1)$ \\
\hline C23 & ST & $(0.75,1,1)$ \\
\hline C24 & ST & $(0.75,1,1)$ \\
\hline C25 & ST & $(0.75,1,1)$ \\
\hline C3 & ST & $(0.75,1,1)$ \\
\hline C31 & T & $(0.5,0.75,1)$ \\
\hline C32 & ST & $(0.75,1,1)$ \\
\hline C33 & C & $(0.25,0.5,0.75)$ \\
\hline C34 & C & $(0.25,0.5,0.75)$ \\
\hline C35 & C & $(0.25,0.5,0.75)$ \\
\hline C4 & T & $(0.5,0.75,1)$ \\
\hline C41 & ST & $(0.75,1,1)$ \\
\hline C42 & T & $(0.5,0.75,1)$ \\
\hline Sel
\end{tabular}

Selanjutnya dibutuhkan bobot global sub kriteria yang berasal dari perkalian antara bobot subkriteria dengan masing-masing kriteria utama. Hasil perhitungan bobot global sub kriteria ditunjukan pada tabel 4.

Tabel 4. Bobot global tiap sub kriteria

\begin{tabular}{cc}
\hline Sub Kriteria & Bobot Global \\
\hline C11 & $(0.0625,0.25,0.5625)$ \\
\hline C12 & $(0.0625,0.25,0.5625)$ \\
\hline C13 & $(0.0625,0.25,0.5625)$ \\
\hline C21 & $(0.25,0.5625,1)$ \\
\hline C22 & $(0.25,0.5625,1)$ \\
\hline C23 & $(0.375,0.75,1)$ \\
\hline C24 & $(0.375,0.75,1)$ \\
\hline C25 & $(0.375,0.75,1)$ \\
\hline C31 & $(0.375,0.75,1)$ \\
\hline C32 & $(0.5625,1,1)$ \\
\hline C33 & $(0.1875,0.5,0.75)$ \\
\hline C34 35 & $(0.1875,0.5,0.75)$ \\
\hline C41 & $(0.1875,0.5,0.75)$ \\
\hline C42 & $(0.375,0.75,1)$ \\
\hline
\end{tabular}


Hasil evaluasi derajat kecocokan alternatif terhadap kriteria ditunjukan pada tabel 5

Tabel 5. Bobot global tiap sub kriteria

\begin{tabular}{cccc}
\hline Sub & \multicolumn{3}{c}{ Derajat Kecocokan } \\
\cline { 2 - 4 } Kriteria & A1 & A2 & A3 \\
\hline C11 & SB & B & B \\
\hline C12 & B & SB & C \\
\hline C13 & SB & SB & B \\
\hline C21 & B & SB & B \\
\hline C22 & SB & B & B \\
\hline C23 & SB & SB & B \\
\hline C24 & B & SB & B \\
\hline C25 & B & B & B \\
\hline C31 & B & C & C \\
\hline C32 & B & SB & B \\
\hline C33 & SB & B & B \\
\hline C34 & B & C & C \\
\hline C35 & B & B & C \\
\hline C41 & SB & B & B \\
\hline C42 & C & C & C \\
\hline
\end{tabular}

Selanjutnya, menggunakan persamaan (1) dilakukan agregasi antara bobot kriteria dan derajat kecocokan alternatif terhadap kriteria. Tabel 6 menunjukan Indeks kecocokan fuzzy yang merupakan hasil agregasi

Tabel 6. Indek Kecocokan Fuzzy

\begin{tabular}{cc}
\hline Alternatif & $\mathbf{F}_{\mathbf{i}}$ \\
\hline $\mathrm{A}_{1}$ & $(0.149,0.476,0.846)$ \\
\hline $\mathrm{A}_{2}$ & $(0.146,0.464,0.817)$ \\
\hline $\mathrm{A}_{3}$ & $(0.114,0.392,0.795)$ \\
\hline
\end{tabular}

Langkah 3 : Seleksi alternatif yang optimal.

Menggunakan persamaan (2) dilakukan perhitungan nilai total integral, dengan mengambil derajat keoptimisan $(\alpha)=0$ (tidak optimis), $\alpha=0.5$ dan $\alpha=1$ (sangat optimis). Tabel 6 merupakan nilai total integer untuk setiap alternatif

Tabel 7. Nilai Total Integer

\begin{tabular}{cccc}
\hline Alternatif & \multicolumn{3}{c}{ Nilai Total Integer } \\
\cline { 2 - 4 } & $\boldsymbol{\alpha}=\mathbf{0}$ & $\boldsymbol{\alpha}=\mathbf{0 . 5}$ & $\boldsymbol{\alpha}=\mathbf{1}$ \\
\hline $\mathrm{A}_{1}$ & 0.313 & 0.487 & 0.661 \\
\hline $\mathrm{A}_{2}$ & 0.305 & 0.472 & 0.640 \\
\hline $\mathrm{A}_{3}$ & 0.253 & 0.423 & 0.593 \\
\hline
\end{tabular}

Dari tabel 6 dapat diketahui urutan alternatif dengan nilai total integer tertinggi pada semua derajat keoptimisan adakah $\mathrm{A} 1>\mathrm{A} 2>\mathrm{A} 3$. Sehingga e-marketplace SH menjadi alternatif terbaik sebagai media pemasaran melalui internet.

\section{Kesimpulan}

Pada penelitian ini dilakukan pemilihan e-marketplace menggunakan metode fuzzy decision making dengan kriteria yang digunakan antara lain kualitas pelayanan, kualitas sistem, kualitas sistem informasi dan kualitas penyedia layanan. Terdapat tiga alternatif yaitu TK, BL dan SH. Berdasarkan hasil perhitungan, diperoleh urutan nilai total integral pada semua derajat keoptimisan dengan urutan sebagai berikut $\mathrm{SH}>\mathrm{TP}>\mathrm{BL}$. Dari urutan tersebut, e-marketplace SH dapat dijadikan alternatif terbaik sebagai sebagai media pemasaran melalui internet.

\section{Daftar Pustaka}

[1] OECD. Covid-19: SME Policy Responses. OECD 2020.

[2] Pakpahan AK. Covid19 dan implikasi bagi UMKM. PACIS 2020.

[3] Hardilawati W laura. Strategi Bertahan UMKM di Tengah Pandemi Covid-19. J Akunt Dan Ekon 2020.

[4] Setyorini D, Nurhayaty E, Rosmita R. Pengaruh Transaksi Online (ECommerce) Terhadap Peningkatan Laba UMKM. J Mitra Manaj 2019.

[5] iPrice insights. State of eCommerce in Southeast Asia 2017. IPrice Insights 2017.

[6] Vatansever K, Akgul Y. Applying Fuzzy Analytic Hierarchy Process For Evaluating Service Quality Of Private Shopping Website Quality: A Case Study In Turkey. J Business, Econ Financ 2014.

[7] Kahraman C, Onar SÇ, Öztayşi B. B2C Marketplace Prioritization Using Hesitant Fuzzy Linguistic AHP. Int J Fuzzy Syst 2017.

[8] I C, D B, D M. Supplier selection in electronic marketplaces using satisficing and fuzzy AHP. Expert Syst Appl 2010.

[9] Yuianto E, Wibowo AP. Marketplace Selection Strategy With Integration Of Fuzzy AHP And Fuzzy MOORA Methods. Edusainstech 2020.

[10] Wibowo AP, Yunianto E. Pemilihan EMarketplace Berkualitas Dengan Metode Fuzzy AHP Dan Fuzzy VIKOR. Edusainstek 2019.

[11] Royanti NI, Yunianto E. Pemilihan EMarketplace Bagi Pedagang Batik Pekalongan Menggunakan Metode Fuzzy AHP-TOPSIS. Edusainstek 2018.

[12] Cevikcan E, Cebi S, Kaya I. Fuzzy VIKOR and Fuzzy Axiomatic Design Versus to the Fuzzy Topsis: The Application of Candidate Assessment. J Mult Log Soft Comput 2009. 
[13] Patel D, Thakar G. A Sector Wise Prioritization of Vendor Selection in Supply Chain using Multi-Criteria Decision-Making Method. Int J Comput Appl 2021.

[14] Cakar T, Çavuş B. Supplier Selection Process In Dairy Industry Using Fuzzy Topsis Method. ORESTA 2021.

[15] Nguyen NBT, Lin G-H, Dang T-T. Fuzzy Multi-Criteria Decision-Making Approach for Online Food Delivery (OFD) Companies Evaluation and Selection: A Case Study in Vietnam. Processes 2021.

[16] Arunyanarta S, Sureeyatanapasa P, Ponhan K. International location selection for production fragmentation. Expert Syst Appl 2021.

[17] Momani AM. Using Multi-Attribute Decision Making Approach to Evaluate Learning Management Systems. Int J Web-Based Learn Teach Technol 2021.

[18] iPrice insights. Peta E-Commerce Indonesia. IPrice Insights 2020.

[19] Alptekin N. Evaluation of Websites Quality Using Fuzzy TOPSIS Method. Int J Acad Res Bus Soc Sci 2015.

[20] MOON JH, KANG CS. Application of Fuzzy Decision Making Method to the Evaluation of Spent Fuel Storage Options. Prog Nucl Energy 2001. 